\title{
EDUCAÇÃO DA MENTE E DO CORPO, PROFESSOR PESQUISADOR REFLEXIVO E A CIÊNCIA DO CONCRETO
}

\author{
DRA. TANIA MARA TAVARES SILVA \\ Doutora em Educação pela UNICAMP e docente da UNIRIO \\ (Rio de Janeiro - Rio de Janeiro - Brasil) \\ e-mail : taniamtavares@yahoo.com.br \\ DR. HUGO RODOLFO LOVISOLO \\ Doutor em Antropologia Social pelo Museu Nacional/UFRJ e docente da UERJ e da \\ UNISUAM - Mestrado em Desenvolvimento Local \\ (Rio de Janeiro - Rio de Janeiro - Brasil) \\ e-mail: lovisolo@globo.com
}

\begin{abstract}
RESUMO
A partir das contribuições de Lovisolo (1995), que usa a imagem do bricoleur de Lévi-Strauss para pensar a prática docente, tentamos neste artigo resignificar as contribuições da corrente de formação docente denominada de Professor Pesquisador Reflexivo (PPR). Seus principais autores, sobretudo, Stenhouse, é visto sob a perspectiva que domina em sua interpretação e que enfatiza a autonomia, a criatividade, a arte e posta em contraposição com a perspectiva delineada por Lovisolo a partir dos entendimentos de Lévi-Strauss sobre as formas do pensamento primitivo e científico. Por último, são postas questões sobre o funcionamento do ensino que, o romantismo que vigora no campo da formação do PPR, parece operar recusando tanto esse tipo de questões quanto suas possíveis respostas.
\end{abstract}

PALAVRAS-CHAVE: Professor reflexivo; formação do professor; produção de conhecimento; bricoleur. 
Há mais de duas décadas, Saviani (1989) chamava a atenção para o fato que a história da educação se confundia com a história das ideias pedagógicas, pois a tendência era enfatizar a educação esquecendo-se da história, ou realizando o inverso. Ou seja, através de um texto sobre história da educação tínhamos mais acesso às ideias do que ao que efetivamente acontecia no âmbito das escolas. Para o autor, o equilíbrio poderia ser encontrado se nos centrássemos no que ele denominava bastidores da história.

As pesquisas historiográficas realizadas hoje na área da educação estão mais próximas do proposto por Saviani, já que tendem a centrar-se não só nas ideias pedagógicas, mas como elas se realizam na prática. Ou seja, podemos encontrar tanto descrições sobre como pensavam os educadores brasileiros quanto como era a vida escolar. Para tanto, foi definitivo que a história da educação se embebesse das mudanças operadas no interior da historiografia e que modificaram a maneira de se investigar os acontecimentos históricos. Houve reações a esta abordagem, como afirma Gatti Junior:

A fertilidade das novas abordagens e temáticas apresentadas nas últimas décadas permite afirmar que, mesmo havendo diferenças metodológicas significativas na historiografia atual, elas assinalam, antes de tudo, riqueza interpretativa e pluralidade metodológica. Provavelmente, as mentes ainda presas ao passado, com ideias monolíticas que parecem fazer mais sentido e possuir mais lógica, estejam encontrando dificuldades para absorver tal diferenciação e pluralidade. $\{E\}$ o que parece mais significativo é que os autores e mesmo leitores especializados da produção historiográfica atual se preocupem cada vez menos com questões relacionadas à filosofia da história, evitando, dessa forma, a permanência de discussões por demais abstratas e conduzidas, no mais das vezes, por interlocutores que pouco ou nada sabem do duro trabalho de lidar com o passado, que não sabem nem mesmo o que é trabalho com evidências em história (GATTI JUNIOR, 2002, p. 5).

Podemos inferir, das palavras acima, que a proposta de Saviani tem sido conduzida de forma a termos um campo de pesquisa intelectual que é específico para a história da educação, separada de "questões abstratas" e embasada na evidência histórica. Porém, apenas a título de provocação, gostaríamos de colocar uma questão. Será que não corremos o risco de cair na armadilha de realizar apenas descrições históricas, sem que questões sejam colocadas para as evidências encontradas? Como, então, poderíamos dialogar, se cada pesquisa acabasse tendo uma singularidade tal que não pudesse ser comparada a outras? Não acreditamos que este tenha sido o movimento da historiografia, principalmente o deflagrado pelos Annales que tiveram, como uma de suas características, o diálogo com outras áreas do conhecimento, como, por exemplo, a sociologia, a demografia, a antropologia e a economia. 
A relação entre educação e história descrita por Cambi (1999), apresenta um capítulo inicial que discute os vínculos possíveis entre as duas áreas e os denomina como "Revoluções Historiográficas". Para ele, o marxismo, a pesquisa dos Annales e a história total; a contribuição da psicanálise; e o estruturalismo e as pesquisas quantitativas, foram movimentos que tenderam a modificar a história da educação criando âmbitos historiográficos autônomos, mas que dialogam entre si. Um destes novos âmbitos é o que o Cambi denomina de "mentalidades educativas, de valores pedagógicos e de práticas formativas" ( 1999, p. 31). O novo olhar proposto pelo autor incorpora a maneira como modificamos, no tempo, as representações do que sejam as práticas educativas no interior das quais podemos incluir a atuação docente nas várias áreas disciplinares. Destas, também fazem parte a Educaçãa Física ou, mais especificamente, a Educação Física Escolar.

Tendo por base o proposto por Cambi, podemos alocar nosso texto no eixo historiográfico que procura analisar as mentalidades educativas a partir de novas propostas para a prática docente. Trata-se do que tem sido denominado de história do presente, já que a análise centra-se na década de 1990, reconhecida como fundamental para a História da Educação, pois é neste período que se consolidam as Reformas Educacionais que já vinham sendo gestadas na década anterior. Neste período as políticas públicas em relação à educação foram novamente modificadas e, o que mais interessa, elas incluem um novo papel para o docente que está presente tanto em documentos oficiais como em textos acadêmicos.

Focalizaremos nossa lente de análise do papel docente na corrente que propõe a prática orientada pela pesquisa e pela reflexão sobre a própria prática. Rota que é considerada pelos seus defensores como profícua para que se estabeleça uma melhoria na relação ensino-aprendizagem além de tornar o docente como alguém que produz novos saberes e não apenas reproduz o que já existe.

Quando nos centramos na história da formação docente vemos que ela tem se dedicado a escrutinar, através de fontes orais ou escritas, de que maneira construímos um caminho que, historicamente, começa com o mestre, ou seja, a escola do período colonial, e chega até os dias de hoje e caracteriza a docência como profissão (VILLELA, 2000). Um dos pontos fundamentais desta reconstrução tem sido, por um lado, analisar o docente sob a ótica da objetividade (um profissional com uma formação definida, que trabalha sob determinadas normas regidas por lei e políticas educacionais) e, por outro lado, sob a perspectiva que enfatiza a subjetividade (sua história pessoal, sua memória como aluno ou aluna, dentre outros). Esta perspectiva também domina na análise do professor de educação física escolar como, por exemplo, os textos de Graça (2004) e Teves (2004). Parece claro, portanto, que tal divisão está muito mais ligada a uma questão de ênfase do que de negação 
da relação entre o objetivo e subjetivo. Ou seja, na ação docente, é cabível pensar que os dois lados estão presentes. Isso significa reconhecer que o docente, na sua prática, reporta-se tanto à sua história pessoal quanto à sua formação profissional. E é por esta perspectiva que iremos propor nossa análise sobre a proposta do Professor Pesquisador Reflexivo.

Como já mencionado, o período escolhido para a análise concentra-se nos anos de 1990, quando é publicada a Lei de Diretrizes e Bases' (LDB) e, em 1999, os Referenciais para a Formação de Professores (BRASIL, 1999) de forma conjunta com a implantação do Curso Normal Superior como específico para a formação do docente das séries iniciais. Étambém nos anos de 1990 que ocorre a difusão, no Brasil, da vertente de formação do PPR. São dois os principais eventos que marcam este movimento. Em primeiro lugar, a divulgação feita no Brasil de um livro organizado por Antonio Nóvoa ( 1992), no qual constam três artigos cuja temática comum é o Professor Pesquisador Reflexivo (PPR). O segundo momento é a participação de pesquisadores brasileiros no I Congresso de Formação de Professores em Língua Portuguesa, que aconteceu em Portugal, na cidade de Aveiro, em 1993. Naquele evento privilegiou-se o saber e a memória docente como fundamentais para os movimentos de melhoria e mudança na atuação dos professores (PIMENTA, 2002).

A vertente do PPR torna-se importante na medida em que difundiu, de forma conjunta com outras perspectivas, o que hoje se constitui em proposições que enfatizam a importância do "saber docente" para a criação de uma nova forma de intervenção dos professores. Assim, a pesquisa, a reflexão e a memória tornaram-se categorias chave para a transformação da atuação dos professores, no sentido de responder às necessidades postas pelas mudanças históricas advindas de um processo que culminou na promoção de reformas educacionais em vários países, dentre eles, os da América Latina. Assim, a proposta desta nova mentalidade educativa, denominada PPR, se consolidou como proposta de formação e atuação docente nos anos de 1990, embora suas raízes remontem aos anos de 1940, como mostram Lisita, Rosa e Lipovetsky (2005).

O objetivo do artigo é analisar um autor desta vertente, buscando interpretar suas ideias a partir de referenciais antropológicos. Ou seja, trata-se de alargar a perspectiva da interdisciplinaridade, dado que iremos tomar duas áreas de conhecimento específicas - a educação e a antropologia -, e do espectro mais amplo de ambas, a história da formação docente e o estruturalismo antropológico, aqui representado por um dos "pais fundadores", Lévi-Strauss. É preciso acrescentar que a vertente do PPR também tem se firmado como forma de atuação docente na Educação Física,

I. Brasil (1996). 
como pode ser visto em textos recentes, como, por exemplo, o de Barbosa-Rinaldi (2008). Apoiando-se em Pimenta (2002), a autora escreve:

Ao reconhecer a quantidade e a velocidade das informações na sociedade de hoje, postula que um profissional precisa estar preparado 'científica, técnica, tecnológica, pedagógica, cultural e humanamente e deve ser um profissional que reflete sobre o seu fazer pesquisando-o nos contextos nos quais ocorre. Para tanto, ao assumir que a atividade docente é práxis, afirma que o professor deve ser visto como um intelectual que está sempre em formação e que a educação é um processo dialético no qual o homem se desenvolve historicamente. Propõe que a identidade do profissional docente deva superar o papel de '[...] professores reflexivos para o de intelectuais críticos e reflexivos. [portanto] é necessário preparar os futuros professores para serem promotores de seu próprio de desenvolvimento profissional e, para isso, os autores defendem a epistemologia da prática reflexiva ressaltam a necessidade de desenvolver a capacidade reflexiva e investigativa do professor, para que assim, possam entender a complexidade que envolve a prática educacional (BARBOSA-RINALDI, 2008, p. 200).

Na concepção da autora, construir este PPR deve ser a orientação dada nos cursos de formação, principalmente através de situações problemas, para as quais os futuros professores devem ser preparados. Para tanto, as práticas pedagógicas têm que existir nos primeiros anos de formação e no estágio supervisionado. As ideias da autora promovem o que se convencionou denominar na esfera da educação a "produção do saber docente" que reforça a ideia de que os professores não seriam meros reprodutores do conhecimento, mas produziriam conhecimento nas suas práticas pedagógicas.

Stenhouse, o autor que escolhemos como representante do PPR valorizava a aula como o espaço da construção do saber do professor. Além disto, acrescentava a importância da "criatividade" como fundamental para que, da ação e reflexão, surgissem novas práticas de docente. Stenhouse assimila a prática docente à artística.

\section{A FORMAÇÃO DOCENTE EXTRAPOLA A PEDAGOGIA}

Sabemos que a preocupação com a formação docente extrapola o âmbito da área da Pedagogia e dos pedagogos. A ação de formação docente, em seus desdobramentos, também é foco de interesse daqueles que, em diversos campos de trabalho, formam capacitadores, instrutores, formadores em diversas áreas do conhecimento, especialmente nas denominadas aplicadas ou de intervenção que, frequentemente, exigem a articulação de conhecimentos científicos e técnicos historicamente diferenciados. São, portanto, enfoques multidisciplinares ou interdisciplinares. 
Os que produzem trabalhos sobre o tema da formação docente dão pistas interessantes para que possamos compreender e alargar o campo de aplicação de afirmações que, em princípio, foram apropriadas pelo âmbito específico da Pedagogia, embora não tenham sido direcionados apenas para ele.

Há mais de dez anos, Lovisolo (1995), enfocando o problema da formação do profissional de Educação Física, elegia como tema para reflexão, discutir as conseqüências que poderiam advir na prática profissional, de uma formação multidisciplinar. Para o autor:

Um educador físico suporta um currículo de formação que vai da mecânica à filosofia, passando pela fisiologia, a neurologia, a biologia, a sociologia, as ditas ciências da educação e a história entre as outras áreas disciplinares. [...] Este caráter da formação não implica que se baseie em formas consensuais e satisfatórias de integração ou relacionamento das diversas disciplinas que entram no currículo. De fato, e este é um problema sério na formação, as disciplinas podem ser entendidas como compartimentos sem graus apreciáveis de comunicação (LOVISOLO, 1995, p. 30).

O problema apontado pelo autor pode ser transposto, com facilidade, para os cursos de Pedagogia. Na maioria destes, há também um currículo multidisciplinar que, em vários casos, tende a separar as denominadas disciplinas de fundamento daquelas com ênfase na prática. Transpor esta barreira, ou seja, estabelecer uma relação entre teoria e prática, tem sido uma constante nos cursos e uma preocupação comum nos textos que tratam da formação docente como, por exemplo, Gatti (20 I 0) e, em especial, os que defendem a proposta do Professor Pesquisador (ESTEBAN; ZACCUR, 2002).

Uma das saídas, cada vez mais enfatizada, tem sido a inserção da pesquisa como uma disciplina que poderia realizar um diálogo integrador, embora parcial, entre as várias disciplinas ou áreas de conhecimento. Porém, ainda não existe produção suficiente para sabermos se esta é uma saída para, efetivamente, amalgamar a formação. A dificuldade cresce quando consideramos que existe um espectro variado de modelos ou tipos de pesquisa e que, por vezes, há sérias oposições entre os docentes, que vão desde o campo epistemológico até o das técnicas. Para ficar mais claro, basta citar algumas das oposições presentes no campo educacional. Por exemplo, com a oposição entre pesquisas quantitativas e qualitativas, entre o método dialético e o positivista, entre compreensão e explicação, entre objetividade e subjetividade. Todas geram polêmicas e mal entendidos, quase sempre entrópicos ou desorganizadores da proposta de conferir à pesquisa um papel integrador ou dialógico. Ao contrário, a pesquisa também parece funcionar como divisor de águas. Otrabalho de distinguir entre divisões superficiais (de linguagem e iluminação) das profundas (disposições e teorias) necessita ser ainda realizado. 
Temos, portanto, como continuidade deste processo ainda não resolvido o mosaico das disciplinas reforçado por uma estrutura escolar e administrativa (e muitas vezes corporativa), particularmente mais forte em instituições de ensino superior particular, onde, como é sabido, forma-se a maioria dos pedagogos. A própria organização do regime de trabalho, apoiada, principalmente, na contratação do professor "horista", dificulta a realização das propostas de integração ou de diálogo, o que demandaria outro tipo de matriz curricular e de organização da instituição educativa. Outros agravantes, abundantemente referidos na literatura, aprofundam a separação entre a operação da Educação Física Escolar e as outras disciplinas, mais ainda quando domina a crença de que ela se ocupa do corpo e da diversão, enquanto as outras trabalham a formação da mente e a moral. Além disto, temos que reconhecer que também não está claro que exista um avanço significativo da integração disciplinar ou de conteúdos nas instituições que contam com alto percentual de professores em regime de dedicação integral, mesmo sendo estas, majoritariamente, públicas².

Este quadro de dificuldades deixa em aberto outras possibilidades de abordagem da questão. Mas, voltando à proposta deste texto, recuperamos de Lovisolo o seu diagnóstico de que esta dificuldade de integração coloca o profissional educador físico "muito próximo da figura do bricoleur, de Lévi-Strauss, que a partir de fragmentos de antigos objetos, guardados no porão, constrói um objeto novo no qual suas marcas não desaparecem" (LOVISOLO, I 995, p. 31). O produto do agir do bricoleur resulta, dadas às condições de elaboração, em um objeto único, cuja possibilidade de teste e repetição é muito baixa.

A imagem do bricoleur se aplica ao docente que enfatiza seu "método" ou "jeito" de fazer o próprio processo de ensino e aprendizagem. Ele também fabrica seu agir a partir de objetos ou fragmentos de seu estudo e de experiência feitos de memória. Observemos que a reivindicação da autonomia docente pode funcionar como escudo de proteção do "método" ou "jeito" diante do olhar avaliativo e, até, da intervenção que pretende sua formação. A autonomia pode ser apenas uma recusa de interesses diferentes (estudantes, responsáveis, políticos ou, autoridades administrativas, entre outros) que freia a mudança ou transformação tão enfatizada pelos pedagogos. Mais ainda, se a educação é tarefa de todos, a autonomia o que pode significar? Será que ela recusa a influência dos outros, a negociação, a mediação?

2. É importante esclarecer que existe um universo de instituições particulares que mantém professor contratado para dedicação exclusiva, o que significa, quase sempre, o investimento em pesquisa. No entanto, sabe-se que tal realidade, a de dedicação à pesquisa, no caso brasileiro, tem sido quase uma exclusividade da rede pública, tanto a federal como a estadual. 
E se isto é assim, como fazer da educação dos novos uma tarefa de todos? O que queremos dizer é que a autonomia pode se constituir em uma possível armadilha, pois tanto pode ser um valor positivo, como também uma mera defesa para um modo não adequado do agir docente.

A imagem do bricoleur nos parece ser hoje muito apropriada para que possamos explicar a ênfase de um conjunto de produções sobre a formação de professores: a que enfatiza a reflexão sobre a prática docente. Da vertente do PPR iremos extrair a ênfase em duas ideias: a) que o docente, ao refletir sobre sua prática, constrói algo novo e b) que o professor é um artista. Estas duas perspectivas, embora presentes de forma implícita em vários autores aos quais se atribui esta filiação (LISITA; ROSA; LIPOVETSKY, 2005), são enfatizadas por Stenhouse, um dos "pais fundadores" desta matriz pedagógica. Observemos que ambas as ideias ou afirmações parecem funcionar muito mais como norte (prescrição) do processo de formação reflexiva, do que descrição do mesmo, especialmente nas apropriações feitas no Brasil, no campo pedagógico (dos argumentos de Stenhouse). Ver-se-á que caminharemos na direção de propor uma interpretação um tanto diferente das realizadas e que, acreditamos, permite desenvolver fundamentos mais claros.

Analisaremos as duas ideias colocadas no parágrafo anterior tomando como eixo a comparação entre as ideias de Stenhouse e as análises de Lévi-Strauss reunidas em seu ensaio A Ciência do Concreto, e que foram citadas por Lovisolo (1995).

Para executar esta tarefa iremos, inicialmente, retomar a proposta do PPR de forma geral e, também, as ideias de Stenhouse. Por fim, entender as ideias deste sob a luz de Lévi-Strauss, lembrando que este autor não escreveu sobre formação de professores e sobre educação, à exceção de uma comunicação intitulada Palavras Retardatárias Sobre a Criança Criadora (1986). A constante no seu trabalho foi, quase sempre, a compreensão dos grupos tribais (ou "sociedades primitivas") e, mais particularmente, a relação entre estas sociedades e a sociedade do homem ocidental. Ou, ainda mais especificamente nos termos antropológicos, entre sociedades simples e complexas. Seu objetivo foi, especialmente, procurar estabelecer o que ele denominava "estruturas universais", as quais estariam presentes na base da construção da diversidade cultural. No ensaio que vamos retomar este é também o centro de sua análise.

\section{A PROPOSTA DO PPR: A ÊNFASE NA TRANSFORMAÇÃO DA SOCIEDADE}

Desde que a proposta "aportou em terras brasileiras", os defensores do PPR ampliaram-se e se tornaram referência, implícita ou explicitamente, em textos oficiais. Iremos agora destacar os pontos que consideramos chave no interior das 
proposições que dizem respeito à visão de mudança que apresentam para a educação e para a intervenção docente, a partir do suposto que a reflexão sobre a prática engendra transformação social. Como já dito, os que abraçaram esta proposta, foram impulsionados, por publicações e eventos que se centraram na pesquisa, na reflexão e na importância dos saberes e memória docente, a base para a "criação" de novas práticas de ensino e, por consequência, para a formaçãa de um professor com nova mentalidade educativa.

A importância da pesquisa para a formação docente e a ideia do professor pesquisador, tal como é veiculada hoje, tem por trás uma história e uma concepção de educação; de currículo e de sociedade, que a alicerça. Segundo Lisita, Rosa e Lipovetsky (2005) é possível identificar na literatura mais recente sobre formação de professores quatro perspectivas norteadoras: a acadêmica, que enfatiza o conteúdo; a da racionalidade técnica, cuja ênfase é a formação de um técnico que age conforme regras e técnicas oriundas do conhecimento cientííco; a prática que destaca a formação na e para a prática e, por fim, a perspectiva da reconstrução social, que tem como proposta a formação de um profissional crítico, cujos princípios devam ser favoráveis à justiça social.

Na perspectiva da reconstrução social, as autoras apontam uma subdivisão: há os que defendem um ensino que seja comprometido com a transformação da sociedade (cuja base é a pedagogia crítica ou teoria crítica) e os que se preocupam com modificações no âmbito do ensino, isto é, que este se caracterize por ser mais democrático, sem "se definir claramente por um paradigma de sociedade diferente do atual” (LISITA; ROSA; LIPOVETSKY, 2005, p. I09). Com base nesta subdivisão, classificam como exemplos da primeira "corrente", Giroux e Zeichner e, para a segunda, Stenhouse e Elliot. Estamos supondo que o leitor, profissional da Educação Física, conhece os trabalhos clássicos que se situam na perspectiva da transformação social, especialmente as posições do grupo reconhecido como Coletivo de Autores (SOARES et al., 1992) e da modificação no âmbito do ensino da Educação Física escolar (aqui os representantes não estão claramente agrupados) e pode facilmente construir as pontes com o campo dos pedagogos.

É plausível inferir da descrição em pauta que a ideia, ou melhor, o conceito de transformação da sociedade, estaria presente de forma diferente nas duas propostas. Assim, segundo as autoras, para Giroux e Zeichner a transformação do ensino traria como consequência a construção de uma sociedade diferente da atual. Já para Stenhouse e Elliot, a modificação iria ocorrer no âmbito do ensino e, por meio desta mudança, a transformação social (uma sociedade mais justa), o que não significa a modificação da sua estrutura. Ainda de acordo com as autoras, embora separadas por aquilo que pretendem transformar, a perspectiva da reconstrução 
social reconhece, como princípio, que é incerta e complexa a natureza do trabalho docente $^{3}$. E, continuam,

[...] defendem a construção do conhecimento sobre o ensino pelo professor, por meio de sua própria reflexão, o que requer uma formação docente que lhe possibilite teorizar sua prática, participar da produção de seu conhecimento profissional, propor mudanças e agir de forma autônoma, tanto no contexto de sua atuação quanto no contexto social mais amplo (LISITA; ROSA; LIPOVETSKY, 2005, p. I09, grifos nossos).

Na citação, as autoras assumem uma das interpretações sobre o lugar da educação, que a considera como determinante do agir autônomo. Vemos, portanto, que as propostas se encontram, novamente, na ideia de transformação tomada por um outro princípio: a mudança na forma de atuação do professor possibilitaria a mudança na sociedade e estaria alicerçada em atitudes como: ser autônomo, participativo e reflexivo que, em um sentido amplo, é entendido como a possibilidade de teorizar sobre a sua própria prática. ${ }^{4}$ Estes, diríamos, podem ser considerados os pontos nevrálgicos e centrais presentes nas propostas do PPR que, em vários sentidos, compõem atitudes desejáveis para o trabalhador em um mundo globalizado (SILVA, 2005).

\section{A PROPOSTA DE STENHOUSE: UMA SÍNTESE}

Iremos contextualizar as ideias e propostas de Stenhouse, enfatizando aquelas que nos possibilitam entender a ênfase na criatividade do professor como ponto nodal para a sua atuação transformadora.

Consta da biografia de Stenhouse, apresentada por alguns autores (CARBONELL et al., 2003), a importância da criação por ele e alguns colegas do Centre for Applied Research in Education (CARE), na University of East Anglia, para o desenvolvimento de pesquisas que focavam a importância do professor pesquisador. Nesse local durante toda a década de 1970 até o início dos anos de 1980 (Stenhouse falece em 1985) foram realizadas pesquisas com ênfase nos estudos sobre escolas e salas de aula, como fundamentais para ajudar os professores a desenvolver ideias alternativas a partir de seu próprio trabalho. Para ele, a pesquisa educativa era uma forma de pesquisa-ação e as classes reais deviam ser laboratórios sob o comando dos professores. Pensar sua própria prática transformaria os professores em aprendizes e sua autoridade passaria

3. Uma análise mais crítica da leitura realizada pelos educadores brasileiros sobre a vertente do PPR pode ser encontrada em Silva (2005).

4. Como veremos, teorizar sobre a prática se constituirá como um debate, dado que não há o mesmo entendimento sobre o significado dessa ação. No entanto, a reflexão do professor terá sempre como base a própria prática. 
de algo "dado" para algo "construído". Para ele, a autoridade do saber não devia ser garantida na maestria e sim na exposição sistemática desta autoridade a erros de fato ou de juízo. Pareceria que estamos diante de certa influência popperiana: o agir deve ser testado e os erros reconhecidos e o aperfeiçoamento seria, então, resultado da correção daqueles. Assim, os professores se tornariam aprendizes de forma conjunta com seus alunos, em curioso paralelo com a formação de orientadores e orientandos, no campo da produção científica. É deste modo, também, que algo novo poderia ser criado dentro de um currículo pré-estabelecido, em analogia com o campo da disciplina na atividade científica. A criatividade do professor estaria, portanto, não no conteúdo dado, mas na forma com que ele estabelece a ação docente como processo e na maneira como age respeitando o que é peculiar em cada aluno.

Para Stenhouse, o caminho dado pela pesquisa-ação (pesquisar sua prática) se afigura como um processo a partir do qual autonomia docente seria possível e este processo teria como base o currículo. Dickel (1998), abordando as ideias de Stenhouse, escreve:

currículo exige do professor conhecimentos, sensibilidade, capacidade de reflexão e dedicação profissional (...) No seu entender, trata-se de um meio através do qual o professor aprende, semelhante a um artista, a arte de ensinar mediante o exercício de seu próprio "que fazer" (DICKEL, 1998, p. 46-47, grifos nossos).

A autonomia e a criatividade do professor por meio da pesquisa seriam fundamentais para o desenvolvimento profissional do docente. $O$ mesmo poderia ser dito substituindo professor por cientista. Isto porque na medida em que busca compreender as situações concretas apresentadas em seu trabalho, constrói uma capacidade de investigar sua própria atuação docente. Não se trata, porém, como já afirmamos, de um processo que se faz de forma aleatória e sem esquemas como, equivocadamente, pode suscitar a comparação com o artista. Como veremos a seguir, o conceito de artista proposto por Stenhouse e sua ideia de pesquisa-ação pode ser comparada à de bricoleur proposta por Lévi-Strauss em um sentido que daria mais crédito e possibilidade de que a proposta deste autor fosse compreendida de maneira correta pelos autores brasileiros. Trata-se não de uma transformação da sociedade, mas da transformação da docência.

\section{O PROFESSOR PESQUISADOR E O BRICOLEUR: APROXIMAÇÕES POSSÍVEIS}

Lévi-Strauss em A Ciência do Concreto ( 1976) está preocupado em demonstrar que a lógica do pensamento selvagem (ou "primitivo", entendido como primeiro), 
é similar à lógica do pensamento moderno. Na verdade, sua preocupação é se contrapor à ideia de alguns antropólogos e sociólogos, que afirmavam que os indígenas se interessavam pela natureza na medida de sua utilidade. Ou seja, que sua relação com as plantas e animais restringia-se a conhecer o que é útil. Lévi-Strauss mostra, retomando vários inventários sobre a relação dos povos indígenas com a natureza, oriundos de várias partes do globo, que os "primitivos" classificavam, como úteis e interessantes, apenas o que conheciam. Dito de outra forma: o conhecimento antecedia a utilidade. Uma posição recorrente entre os cientistas que afirmam que da boa ciência surgem os benefícios ou utilidades (LOVISOLO, 2000). Para Lévi-Straus, isto se dava porque a necessidade de agrupar seres e coisas é, na verdade, uma necessidade do intelecto (seja ele primitivo ou moderno), em impor um princípio de ordem no universo. Portanto, é possível afirmar que o mesmo se passa com primitivos e cientistas: ambos convivem com a dúvida, mas não com a desordem. Assim, afirma o estruturalismo, esta exigência de ordem está na base do pensamento primitivo porque está na base de qualquer pensamento.

Após enfocar este aspecto da cultura, Lévi-Strauss analisa a relação entre magia e ciência. Colocando-se contrário à ideia de que a magia antecede a ciência, afirma que, na verdade, ambas são classificações de natureza diversa, mas não desiguais. Em lugar, pois, de opor magia e ciência, melhor seria colocá-las em paralelo, como duas formas de conhecimento, desiguais quanto aos resultados teóricos e práticos, mas não pelo gênero de operações mentais que ambas supõem: a ciência, assim como a magia, não existe apenas para a utilidade.

No entanto, fica a pergunta: se o pensamento "primitivo" e o da nossa sociedade são da mesma natureza, como se explica que os primeiros tenham parado no tempo e outros tenham inventado a ciência contemporânea? Para Lévi-Strauss o paradoxo só admite uma solução: é que existem duas formas distintas de pensamento científico. Ambas resultariam não de estádios desiguais do desenvolvimento do espírito humano, mas de dois níveis estratégicos onde a natureza se deixa atacar pelo conhecimento científico.

E aqui surge o que interessa destacar na comparação com a proposta de Stenhouse e do PPR, pois é como se as relações necessárias, objetivo de toda ciência, pudessem ser atingidas por dois caminhos diferentes: um muito perto da intuição sensível, e outro, mais afastado. A ciência primeira, a ciência do concreto, não foi nem seria menos científica e seus resultados não foram nem seriam menos reais e, acrescenta Lévi-Strauss, ainda permanecem como essência da nossa civilização. No nosso tempo, afirma, temos uma forma de atividade que se aproxima 
desta ciência primeira. Trata-se da figura do bricoleur que trabalha com as mãos; é o que está apto a executar um grande número de tarefas diferentes. Mas, a regra do seu jogo é arranjar-se com os seus limites; a composição do conjunto não está em relação com qualquer projeto particular, mas é o resultado contingente de todas as ocasiões que se apresentaram para renovar o seu estoque de coisas concretas. (LÉVI-STRAUSS, 1976, p. 37-38). É neste sentido que podemos fazer uma analogia com a prática cotidiana do professor que opera com um estoque (a memória de sua prática e de outras práticas que o influenciaram) que ele foi e vai garimpando ao longo do tempo. Assim, cada elemento (concreto e virtual ao mesmo tempo) singular da história individual do docente poderá adquirir importância em contextos diferentes.

E, para Lévi-Strauss, se o bricoleur e o cientista apresentam elementos que os diferenciam, é possível aproximar ambos quando pensamos que também o cientista encontra seu campo de atuação limitado pelo período da história no qual se insere e no interior da cultura em que ele atua. Ou seja, o cientista não pode fazer o que quiser, pois tem, assim, como o bricoleur, que inventariar um conjunto pré-determinado de conhecimentos teóricos e de meios técnicos. Mas, o que os separa? O cientista, afirma Lévi-Strauss, ao inverso do bricoleur que trabalha por meio de signos, que são limitados, opera por conceitos, que são ilimitados. $O$ cientista procura sempre, mesmo diante das limitações, ir além do que já existe. Ele abre passagem para o novo e quer ultrapassar seu próprio tempo.

Inspirado em Lévi-Straus, Lovisolo denomina a operação do docente como arte da mediação entre valores, objetivos, conhecimentos e técnicas, enfim, como arte de mediar entre o que idealiza e as condições concretas do agir docente. Podemos, agora, centrar-nos na visão do artista tomando, como base, a figura do cientista e do bricoleur. Para Lévi-Strauss

[...] a arte se introduz a meio caminho entre o conhecimento científico e o pensamento mítico ou mágico; pois todos sabem que o artista tem, por sua vez, algo do cientista e do bricoleur: Com meios artesanais ele confecciona um objeto material, que é, ao mesmo tempo, um objeto de conhecimento (LÉVI-STRAUSS, 1976, p. 43).

Eis, portanto, uma compreensão mais correta do que afirmava Stenhouse. O professor, como o bricoleur, refaz um conjunto a partir de peças singulares; mas deve, para ser um artista, ultrapassar o limite do concreto, isto é, abrir passagem para o novo, ou seja, elaborar questões cujas respostas ainda não foram dadas. Só assim ele pode ser um artista que confecciona algo que é material e, ao mesmo tempo, é também conhecimento. 


\section{CONSIDERAÇÕES FINAIS}

A imagem da formação docente conforme a mediação da pesquisa é, sem dúvida generosa, rica e aberta. $\bigcirc$ docente enquanto artista do material e do conhecimento, com algo de cientista e de bricoleur, forma uma imagem poderosa em termos de valor, de desafio e de prazer do agir. Surge, no entanto, uma questão prática: será que é possível a formação da massa de docentes artistas e pesquisadores necessária para uma educação democrática, de massas ou universal? Será que Stenhouse forma parte dos sonhadores de uma educação onde o desafio e a aventura, aliadas do prazer do processo, caminham juntos com outras propostas que enfatizam os mesmos valores e que parecem, reiteradamente, serem derrotadas por uma realidade que demanda protocolos de ensino e de aprendizagem padronizados a partir de uma redução técnica? Eis uma questão fundamental que deve ser respondida por aqueles que defendem a proposta do PPR e que nós, aqui, tentamos analisar, retirando a roupagem romântica que, na maioria das vezes, parece cercar as denominadas propostas inovadoras. Portanto, não basta que educadores tentem promover uma nova abordagem para a ação docente; é preciso que a inovação seja pensada a partir das condições concretas de atuação profissional.

No caso específico da Educação Física Escolar, os docentes teriam que achar novos caminhos (até inusitados), para poder vencer a barreira da precariedade estrutural das escolas. Como um bricoleur, deve tentar agir com o que tem à mão e, quem sabe, criativamente, ampliar as possibilidades do fazer docente na área, o que não invalida a luta para que tenham melhores condições de trabalho. Enfim, o que estamos propondo, é seguir Stenhouse e fazer da aula um laboratório de experimentações pedagógicas apoiadas, inclusive, nos que propagam esta forma de ação como profícua para o ensino-aprendizagem.

\section{Education of the mind and body, and reflective research teacher and the science of concrete}

ABSTRACT: Based on the contributions of Lovisolo (1995), using the Lévi-Strauss bricoleur to think the docent praxis, this article tries to resignify the contributions of the docent formation branch denominated Reflexive Researcher Professor (PPR). Its main authors, specially Stenhouse, are analyzed in a perspective that interpretation dominates and emphasizes autonomy, creativeness, art, putting in opposition with the position delineated by Lovisolo based on understandings of Lévi-Straus about primitive and scientific thinking forms. It is questioned the education functioning that the romantic formation field of PPR seems to operate refusing both this kind of question as its possible answers.

KEYWORDS: Reflexive teacher; teacher formation; production of knowledge; bricoleur. 


\section{Educación de la mente y del cuerpo maestro investigador reflexivo y la ciencia de lo concreto}

RESUMEN: A partir de las contribuciones de Lovisolo (1995) que usa la imagen del bricoleur de Lévi-Straus para pensar la práctica docente, intentamos en este artículo resignificar las contribuciones de la corriente de formación docente denominada de Profesor Investigador Reflexivo (PPR). Sus principales autores, en especial Stenhouse, son vistos en las perspectivas que dominan sus interpretaciones y que enfatizan la autonomía, la creatividad, el arte. Tales perspectivas son puestas en contraposición con los delineamientos de Lovisolo a partir del entendimiento de Lévi-Strauss en el cuadro de la contraposición enre el pensamiento primitivo y científico. Por último, son puestas cuestiones sobre el funcionamiento de la enseñanza que, el romanticismo que vigora en el campo de formación del PPR, parece operar recusando tanto as cuestiones posible cuanto sus respuestas.

PALABRAS CLAVE: Maestror investigador reflexivo; formación de profesores; producción del conocimiento; bricoleur.

\section{BIBLIOGRAFIA}

BARBOSA-RINALDI, I. P. Formação inicial em Educação Física: uma nova epistemologia da prática docente. Movimento, Porto Alegre, v. 14, n. 3, p. 185-207, set./dez. 2008.

BRASIL. Lei n. 9394, de 20 de dezembro de 1996. Estabelece as diretrizes e bases da educação nacional. Diário Oficial da União. Brasília, DF, 23 dez. 1996.

BRASIL. Ministério da Educação. Secretaria de Educação Fundamental. Referenciais para formação de professores. Brasília: MEC / SEF, 1999.

CAMBI, F. História da Pedagogia. São Paulo: Unesp, 1999.

CARBONELL, J. A. et al. (Org.). Pedagogias do século XX. Porto Alegre: Artes Médicas, 2003.

DICKEL, A. Que sentido há em se falar em professor-pesquisador no contexto atual? Contribuições para o debate. In: GERALDI, C. M. G,; FIORENTINI, D.; PEREIRA, E. M. de A. (org). Cartografias do Trabalho Docente. Campinas: Mercado das Letras, 1998. p. 33-72.

ESTEBAN, M. T.; ZACCUR, E. Professora-pesquisadora: uma práxis em construção. Rio de Janeiro: DP\&A, 2002.

GATTI, B. A. Formação de professores no Brasil: características e problemas. Educação \& Sociedade, Campinas, v. 31, n. I13, p. 1355-1379, out./dez. 20 I0. Disponível em: 
< ttp://www.scielo.br/scielo.php?script=sci_arttext\&pid =SO I 0 I-733020 I 00004000 I 6$\& \operatorname{lng}=e n \& n r m=i s o>$. Acesso em: 18 jul. 201 l.

GATTI JUNIOR, D. A história das instituições educacionais: inovações paradigmáticas. In: ARAÚJO J. C. S.; GATTI JUNIOR, D. (Orgs.). Novos Temas em História da Educação Brasileira. Campinas, SP: Autores Associados ; Uberlândia, MG: EDUF, 2002. p. 3-24.(Coleção memória da educação).

GRAÇA, A. E quem nem ensinar sabe, vai para professor de Educação Física... In: LEBRE, E.; BENTO, J. O. Professor de Educação Física: ofícios da profissão. Porto: Saúde Sá artes gráficas, 2004. p. 27-40.

LÉVI-STRAUSS, C. A Ciência do Concreto. In: . O pensamento selvagem. São Paulo: Companhia Editora Nacional, 1976. p. 19-55.

LISITA, V.; ROSA, D.; LIPOVETSKY, N. Formação de professores e pesquisa: uma relação possível? In: ANDRÉ, Marli (Org.). O papel da pesquisa na formação e na prática dos professores. 4. ed. São Paulo: Papirus, 2005, p. 107-127.

LOVISOLO, H. R. Educação Física: a arte da mediação. Rio de Janeiro: Sprint, 1995. Vizinhos distantes: universidade e ciência na Argentina e no Brasil. Rio de Janeiro: Editora da UERJ, 2000.

NÓVOA, A. (Coord.). Os professores e sua formação. Lisboa: Dom Quixote, 1992.

PIMENTA, G. S. Professor reflexivo: construindo uma crítica. In: PIMENTA, G. S.; GHEDIN, E.(Org.). Professor reflexivo no Brasil: gênese e crítica de um conceito. São Paulo: Cortez, 2002. p. 17-52.

SILVA, T. M. T. Professor reflexivo e uma nova (?) cultura da docência: uma análise a partir dos anos 90. 184 f. Tese de Doutorado (Doutorado em Educação). Faculdade de Educação, Universidade de Campinas, São Paulo, 2005.

SAVIANI, D. Do senso comum à consciência filosófica. São Paulo: Cortez, 1989.

SOARES, C. L., et al. Metodologia do ensino na Educação Física. São Paulo: Cortez, 1992.

VILLELA, H de O.S. O Mestre-Escola e a Professora . In: LOPES, E. M. T.; FARIA FILHO, L. M.; VEIGA, C. G. (Orgs.). 500 anos de educação no Brasil. 2. ed. Belo Horizonte: Autêntica, 2000. p. $95-134$. 
Recebido: 10 fev. 2011 Aprovado: 27 jun. 2011

Endereço para correspondência Tânia Mara Tavares da Silva/ Hugo Rodolfo Lovisolo Rua Engenheiro Richard, 219

Grajaú Rio de Janeiro - RJ CEP: 20.561-090 